\title{
Discussion on runoff purification technology of highway bridge deck based on water quality safety
}

\author{
Sheng-guang $\mathrm{TAN}^{1}$, Xue-xin $\mathrm{LIU}^{2,}{ }^{*}$, Guo-ping ZOU ${ }^{1}$, Xin-zhu $\mathrm{XIONG}^{2}$, and Shuang-cheng $\mathrm{TAO}^{2}$ \\ ${ }^{1}$ Jiangxi Ganyue Expressway Co., Ltd, Nanchang, 330025, China \\ ${ }^{2}$ China Academy of Transportation Sciences, Beijing, 100029, China
}

\begin{abstract}
Aiming at the actual problems existing, including a poor purification effect of highway bridge runoff collection and treatment system across sensitive water and necessary manual emergency operation, three kinds of technology, three pools system of bridge runoff purification, the integral pool of bridge runoff purification and ecological planting tank, are put forward by optimizing the structure of purification unit and system setting. At the same time, we come up with an emergency strategy for hazardous material leakage basing on automatic identification and remote control of traffic accidents. On the basis of combining these with the optimized pool structure, sensitive water safety can be guaranteed and water pollution, from directly discharging of bridge runoff, can be decreased. For making up for the shortages of green highway construction technology, the technique has important reference value.
\end{abstract}

\section{Introduction}

With the rapid development of highway construction, frequent traffic activities have raised more attention to the problem of road surface runoff pollution. Carrying large amounts of particulate matter, heavy metals, petroleum, nutrients and PAHs and other pollutants, road runoff put a negative impact on the ecological environment alongside the highway. The pollutants in road surface runoff mainly comes from the wear particles of vehicle tires and road materials, the leakage of hazardous goods in delivery, the particulate matter of snowmelt agent generated from auto parts, the pollutants in rainwater and the atmospheric dust-fall, and the erosion of road surface sediment by rainwater. [1]-[4]

The greatest potential danger to the water body lies in the serious pollution caused by the leakage from carriage of dangerous goods (CDG) due to accidents or some inner factors [5]-[6]. To prevent this kind of environmental risk, in Notice on Strengthening Efforts on Environmental Impact Assessment of Highway Planning and construction (Doc. MEP [2007] No.184), requires that sedimentation tanks are required to set on both sides of the bridges over source water secondary protection area and quasi protection area and Class II water area. Tanks are used for dealing with the bridge surface runoff after the pollution accident so as to ensure drinking water safety.

Since there is no specific design requirement for sedimentation tank, the design of bridge runoff sedimentation tank is mainly used to cope with the requirement of completion acceptance of environmental protection at present. As a result, the design is mostly too simple. Although some studies have optimized the tank structure [7], the overall pollutant precipitation grease effect is limited.

Drain valves were equipped and maintenance staff was required to regularly open the valve to empty runoff. But in fact, there was a long-term presence of sedimentation tank in the full state, resulting that tanks failed to play a role in the hazardous good leakage accident. In response to this kind of problem, researchers began to try to introduce some self-control measures into the bridge runoff emergency management system. Xu Jianping et al [8] proposed a technical system for emergency operation management based on water quality monitoring. However, it still needed to be further demonstrated whether the selected water quality indicators can cover all types of hazardous chemicals. Qin Haiwei et al. [9] proposed a selective collection system of runoff based on real-time monitoring according to different situations. But it lacks the corresponding remote automatic control mode in the disposal strategies.

In view of the above problems, three technologies are proposed to improve the water purification effect of pavement surface by adopting special measures based on smart transport means to ensure water quality and safety, aiming to provide technical support for highway water environment and water safety protection in environment sensitive areas.

\section{The bridge runoff purification emergency three-tank system on different function}

\footnotetext{
* Corresponding author: Xue-xin LIU, nkone@sina.com
} 
The key point of the emergency treatment for hazardous chemical leakage runoff, in daily operations, is a better purifying function for collected runoff. In order to ensure sufficient accident response time during these two function switching processes, an intermediate buffer unit is also needed.

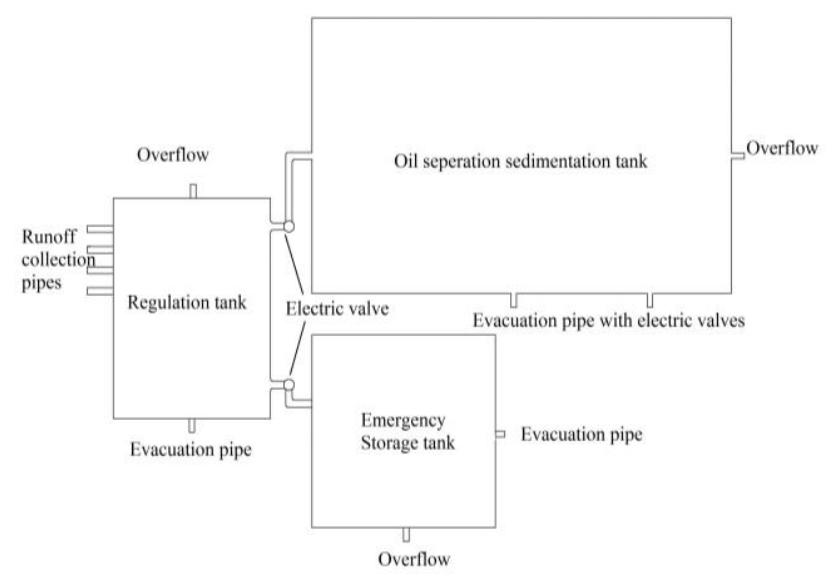

Fig. 1. Bridge runoff purification Emergency three-tank system.

Based on the considerations above, the bridge runoff purification emergency three-tank system was developed. It consists of a storage regulation tank, an oil separation sedimentation tank, an emergency storage tank and a monitoring control system. The surface runoff generated by rainfall firstly enters into the storage regulation tank, which plays a role as a buffer and provides the pretreatment for the bridge runoff.

When there is no leakage of hazardous chemicals, the runoff of bridge deck flows into the oil separation sedimentation tank through the electric butterfly valve which is normally opened. After sedimentation, filtered and purified runoff will be discharged into the surrounding water through the remote control opening the empty pipe valves of storage regulation tank and oil separation sedimentation tank.

When a traffic accident occurs on the bridge, it is first detected through the bridge head monitoring camera and the alarm telephone to determine whether there is any leakage of dangerous goods. After the leakage is confirmed, the monitoring center immediately starts the emergency control system, which orders to open the electric butterfly valve between storage regulation tank and the emergency storage tank, and close the electric butterfly valve between the storage regulation tank and the oil separation sedimentation tank at the same time. Then the leakage of dangerous goods and its dilution collected in storage regulation tank will flow directly into the emergency storage tank for post-treatment offered by the environmental protection department. This kind of technology has been applied to Jiangxi Chang Feng Expressway.

The oil separation sedimentation tank is equipped with baffle wall, pebble retaining wall and oil collection tank. Those kinds of structures are of sedimentation, oil separation and bio-degradation functions and have good removal effects on the primary pollutants in the initial rainfall runoff. Specifically, the vertical bend is set to keep folding flow and improve the sediment separation effect to stay the uniformity of water distribution.

A baffle plate is arranged at the bottom of the vertical baffle wall from top to bottom, which can improve the sedimentation effect of the system. The oil collecting tank is arranged inside the retaining wall. A set of cone mouth with a certain space is designed along the centerline of the bottom of the tank, inside which some nano-fiber oil absorption material is laid to ensure oil separation function of the oil collection tank. The pebble wall set up from the bottom is able to change the direction of water flow, and help with adsorption and biodegradation. The sand tank is set one each before and after the pebble retaining wall at the tank bottom and the blow-off pipe is emplaced one each on both sides of the pebble retaining wall. In addition, the use of electronic valve makes it possible to remote control the emissions when purification reaction time is done.

\section{Coupling remote control of the bridge surface runoff purification and emergency integrated tank}

Bridge runoff purification emergency three-tank system is able to perform the three functions independently, which includes regulation, purification and emergency disposal, and to protect the sensitive water quality to the fullest. However, the project quantity is relatively large and it is more difficult to implement especially when the space under short bridges is limited. So the three tanks mentioned above were combined to form a bridge runoff purification emergency integrated tank with all their functions and the remote control system was optimized.

The various control strategies for the emergency treatment of the bridge runoff are established on the basis of accurate identification of the hazardous chemicals in leakage accident. The accident identification of the three-tank system is worked through the manual confirmation by the camera on the bridge and the alarm telephone, and there is the possibility of

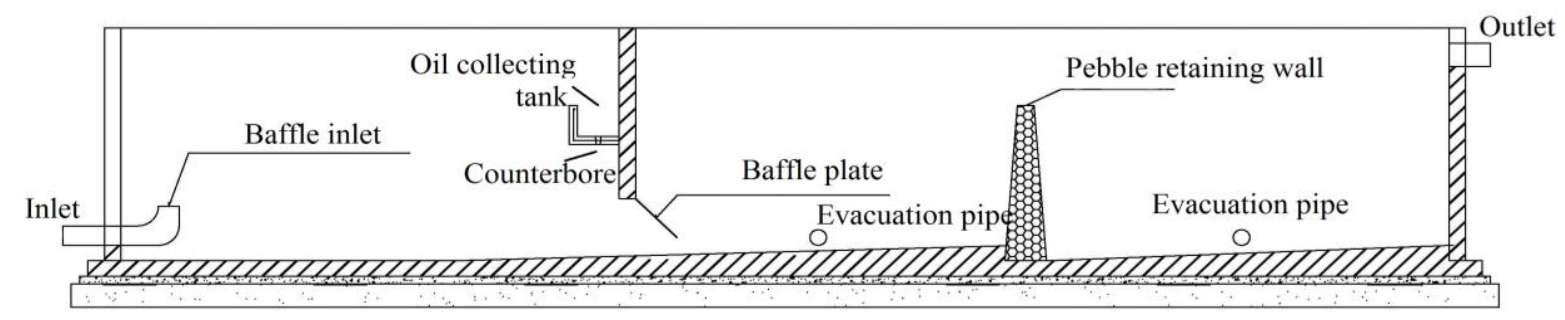

Fig. 2. Oil separation sedimentation tank. 


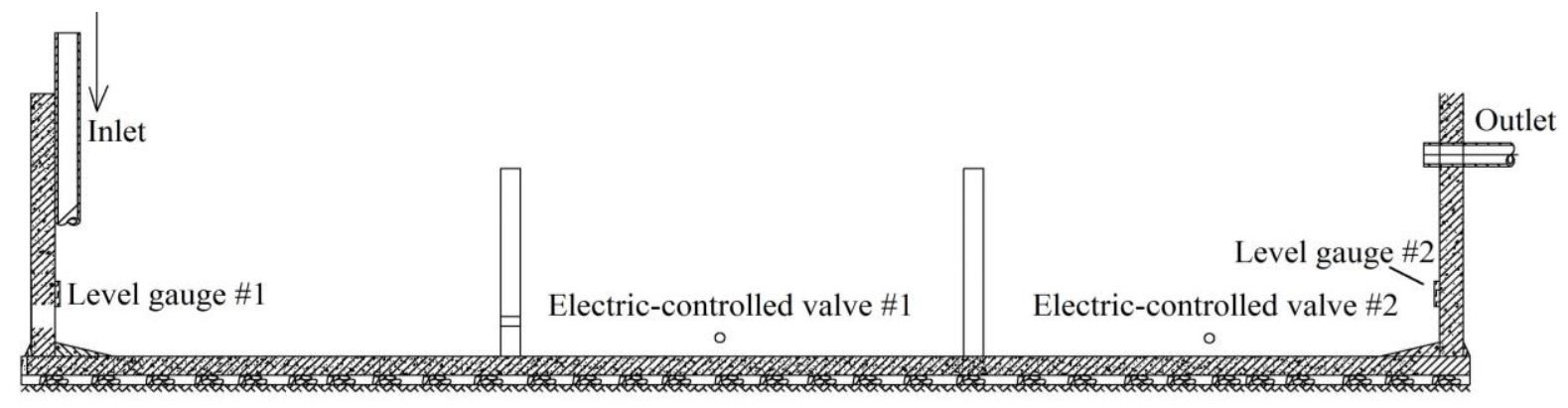

Fig. 3. Bridge runoff purification emergency integrated tank.

missing accidents. Therefore, through the bridge monitor in full coverage, the application of video-based traffic accident detection technology can achieve automatically identifying and issuing a warning to monitoring center. If manual determination ensures that the accident is involved with vehicles carrying hazardous chemicals, and then emergency operation will be confirmed to start, thus the automatic identification of accidents was optimized.

Compared with the oil separation sedimentation tank, the bridge surface runoff purification and emergency integrated tank is simpler in structure. At the same time it integrates the regulating, purifying and emergency disposal functions. There are two sets of retaining walls in the tank, dividing the tank body into three compartments. One plays a role in runoff regulation in water quality and quantity. when hazardous chemical leak accident occurs, the first two cell space with more than $100 \mathrm{~m} 3$ area, can storage the chemicals and its flushing fluid, playing an emergency role. The water flows up and down in vertical baffle way in three cells. Normally, storm-water runoff flows into the tank from the upper part. The water level gradually increased in the first cell, and when the baffle height is reached, the runoff crosses the first baffle into the second cell. Cycling back and forth, the purpose of sedimentation purified layer by layer can be achieved. After the rainfall, the runoff purification is completed. Then the two electrically-controlled outlet drainage valves are remotely opened to realize the emptying function so as to ensure adequate storage space for the next leakage accident.

A group level gauge and electric control valve are set up one each inside the Cell 1 and Cell 3. After the rain stops, purification is also completed. According to the liquid level information, start the blow-off valve remotely to automatically discharge the treated bridge runoff. There are several overcurrent ports at the bottom of the retaining wall between Cell 1 and Cell 3. When the rainwater runoff is in a large amount, the flow passing through the overcurrent port is small. And the runoff will still pass through the first baffle and won't affect the baffle precipitation function. When the runoff in the tank settles, Cell 1 and Cell 2 will form a communication network. Therefore, only a group of level gauge and electronic controlled emptying valve are set up to save cost. This kind of technology has been applied to Heda Expressway in Jilin Province.

\section{Bridge runoff purification emergency ecological planting groove Based on LID}

Due to the extremely low probability of occurrence of hazardous chemicals leakage accidents, no matter the three-tank system or the purification and emergency integrated tank, they are all in masonry structures, which present a poor landscape effect even under the bridge. So they can only be a structure with temporary and limited function. At present, China is vigorously promoting the construction of "sponge city" with natural accumulation, natural infiltration and natural decontamination. Based on the concept of low impact development (LID), various ecological technologies including infiltration, retention, storage, purification, and reuse are integrated for application, thus playing a role in groundwater supplementary, and water cycle regulation [10]. Highway industry has carried out a lot of engineering practice that apply conventional treatment in the bridge runoff treatment and it has achieved initial success. But most of them fail to couple with the accident identification mechanism, so there is still the possibility of tanks full of rains when accident occurs. On the basis, guided by the LID conception, this paper puts forward the bridge runoff treatment process combining regulating tanks and ecological planting grooves, plus equipped with remote control module to achieve intelligent management.

The intelligence level of remote control technology has been further enhanced. It uses the camera with 1080P@30fps high-definition image full-frame detection technology. The real-time video image processing and system self-learning technology is carried to do real-time analysis of video images collected by the camera to identify road traffic accidents. After completing the initiative identification and track detection, it can initiatively remind staff through the sound and light alarming way to observe and deal with it. The alarming image will be immediately switched to the big screen, drawing attention to determine whether emergency operations should be carried out.

The treatment system is a combination of regulation ponds and ecological planting grooves. The pipeline between the regulation ponds and the ecological planting grooves are equipped with an electric-controlled connection valve, and electric-controlled emptying valves are arranged in the ecological planting grooves. 


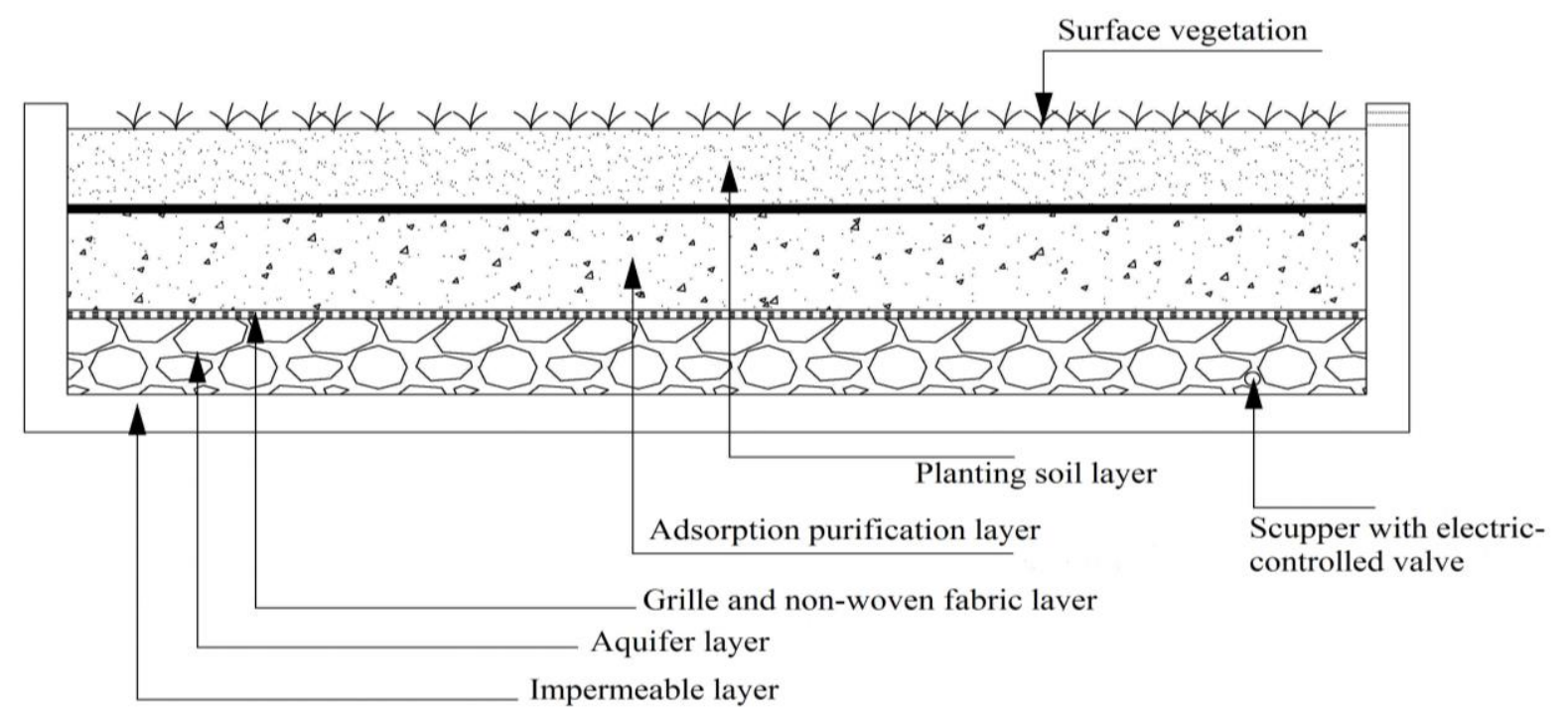

Fig. 4. Ecological planting groove unit.

When the hazardous chemical leakage occurs, staffs are required to shut down the valves remotely to fix the hazardous chemicals and their flushing liquid in the regulation tank with effective volume beyond $100 \mathrm{~m} 3$. Under the extremely special circumstances of hazardous chemicals leakage happening in rainstorm conditions, it is possible that the regulation tank is overflowing. Then the electric-controlled connection valves are supposed to be opened while leaving the emptying valves closed. As a result, the ecological planting tanks are sacrificed in need to fully guarantee the water quality safety.

From top to bottom, each ecological planting groove unit consists of planting soil layer, adsorption purification layer, grille and non-woven fabric layer, aquifer layer and impermeable layer. Planting soil layer contains plants with good water purification effect and local soil, which needs allocation with a poor permeability. With multi-fillers of strong adsorbing and filtering ability for nitrogen and phosphorus removal, adsorption purification layer is the core unit of ecological planting groove. Grille and non-woven fabric, which plays a supporting role, separate the adsorption purification layer from aquifer layer. Filled with stones in a big size, the aquifer layer can make it possible to have reservoir of water, which can be provided for plants without rain. And anti-seepage geotextile is set in impermeable layer to prevent groundwater pollution from the leakage of hazardous contaminants.

This kind of structure has the integrated functions to deal with the bridge runoff, comprehensive utilization and accident emergency, which is an ecological technology with landscape effect. So it can meet the requirements of the green development and sponge city construction in the new era. This technology can also be applied to the road surface runoff purification emergency, which has been applied in Erhai East Lake Road.

\section{Conclusions}

1. The bridge surface runoff treatment three-tank system, the integrated tank and ecological planting grooves are all the new technologies of water protection especially for bridges over the sensitive water body. Compared to conventional technology, the surface runoff purification effect will be better. Due to the utilization of monitoring, accident identification, remote control and other intelligent means, emergency plan can be started in time, preventing the hazardous chemicals into the water body.

2. With the development of smart devices, accident identification and emergency response strategies adopted by the three technologies are still in the process of gradual improvement, and it can be interactively used under different situations. In the future, means of incidents identification should be further enriched to adopt video and microwave interaction technologies to further reduce the misjudgment rate, improving the accuracy of accident analysis.

3. Emergency control of the three technologies is based on accident identification. With the development of environmental monitoring technology, the three technologies mentioned in this paper could be improved with better measures, if the monitoring devices, which are of economic promotion value, could identify all kinds of hazardous chemicals and conventional bridge surface runoff.

4. From the perspective of water purification, the water purification effect increases in the order from the integrated tank, the oil separation sedimentation tank and ecological planting grooves. Besides, the discharge requirements and project cost could also be considered.

5. Under the guidance of green and innovation ideas, referring to new techniques such as sponge city and smart transport could accelerate the improvement of the technical system of water environment protection for bridge-crossing in China.

\section{Acknowledgements}

The research is supported by the science and technology project on transportation construction by Jiangxi Province (No. 2011C00005), the science and technology demonstration project of the Ministry of transport of the 
People's Republic of China (No. 2016002) and the transportation science and technology project of Jilin Province (No. 2017ZDGC-2-8).

\section{Reference}

1. J.S. Wu, C.J. Allan. Characterization and Pollutant Loading Estimation for Highway Runoff. J. Environ. Eng. ASCE 124(7): 584-592 (1998)

2. R.J. Charbeneau, M.E. Barrett. Evaluation of Methods for Estimating Stormwater Pollutant Loads. J. Water Environ. Res. 70(7): 1295-1302 (1998)

3. J.K. Li, G.F. Du, H.E.Li. Purification Effects of Biological Filter on Urban Road Runoff. J. Soil Water Conserv. 26(4): 1-6 (2012)

4. X. Zuo, D. Fu, H. Li. Variation Characteristics of Mercury in Speciation during Road Runoff for Different Rainfall Patterns. J. CLEAN-Soil, Air, Water 41: 69-73 (2013)

5. F. Jia. The Protection Measures Study of Highway Operation Period on Water Environment Sensitive Points. J. Shanxi Sci. Tech. Commun. 5: 94-96 (2015)

6. J.N. Liang, K. Liu, F. Pan. Impact and Protective Measures of Highway Construction in West Mountainous Area on Ecological. Environ. J. China Foreign Highway 30(5): 20-24 (2010)

7. Y.H. Wang, Z.Q. Xiong, Y.T. Shan. Technical Research on Water Environmental Protection in Construction of Renhai-Chishui Expressway. J. Tech. Highway Transport 3: 155-158 (2014)

8. J.P. Xu, S.G. Shao, W.S. Yu. Discussion of Integrated Design of Emergency Storage Facilities of Dangerous Chemicals in Expressway Transport Accidents and Treatment Facilities of Runoff on Bridge Surface. J. Highway Transport. Res. Dev. 31(12): 139-144 (2014)

9. H.W. Qin, L.X. Zhu, X.F. Fu. Selective Collection System of Deck Runoff Based on Real-time Monitoring. J. Yellow River 31(9): 24-25 (2009)

10. D. Zhou. The Application of the Sponge City in Modern City Construction. J. Anhui Agri. Sci. 43(16): 174-175 (2015) 